\title{
LA NARRATIVA DEL CONFLICTO ARMADO INTERNO EN COLOMBIA: UNA CONSTRUCCIÓN POLÍTICA DE LA HISTORIA*
}

\author{
Fanny Esperanza Torres Mora ${ }^{(1)}$, Nathalia Villamizar \\ Yañez ${ }^{(2)}$, Diego Mauricio Sánchez Lozano ${ }^{(3)}$, Jeisson Fabián \\ Porras Moreno ${ }^{(4)}$, Jonathan Harrys Rodríguez Vesga ${ }^{(5)}$
}

THE NARRATIVE OF THE INTERNAL ARMED CONFLICT IN COLOMBIA: A POLITICAL CONSTRUCTION OF HISTORY

A NARRATIVA DO CONFLITO ARMADO INTERNO NA COLÔMBIA: UMA CONSTRUÇÃO POLÍTICA DA HISTÓRIA

Fecha de recepción: 25 de abril de 2016

Fecha de aprobación: 02 de septiembre de 2016

Sugerencia de citación:

Torres Mora, F.E., Villamizar Yañez, N., Sánchez Lozano, D.M., Porras Moreno, J.F. \& Rodríguez Vesga, J.H. (2017). La narrativa del conflicto armado interno en Colombia: una construcción política de la historia. Razón Crítica, 2, 51-77, doi: http://dx.doi.org/10.21789/25007807.1161

* El presente artículo de investigación es resultado de la investigación titulada "Los Hijos de las personas en proceso de reintegración como agentes sociales de reconciliación en el posconflicto: más allá de las categorías dicotómicas de análisis del conflicto colombiano" en el marco de la convocatoria interna de investigación de la Universidad Santo Tomás, Bucaramanga, Colombia. (1) Doctoranda en Sociología y Antropología de la Universidad Complutense de Madrid, España. Licenciada en Ciencias Sociales Universidad Distrital, Bogotá, Colombia. Con Maestría en Antropología Social de la Universidad de los Andes, Bogotá, Colombia, y Máster en América Latina contemporánea y sus relaciones con la Unión Europea: Una cooperación estratégica Universidad Alcalá de Henares, España. Docente e Investigadora de la Universidad Santo Tomas, Bucaramanga, Colombia. http://orcid.org/0000-0002-4329-856X. Correo electrónico: fanytomo@ hotmail.com

(2) Estudiante de Derecho de la Universidad Santo Tomás, Bucaramanga, Colombia. Auxiliar de investigación del Instituto de Victimología y del Consultorio Jurídico de la Universidad Santo Tomás, Bucaramanga, Colombia. http://orcid.org/0000-0001-7071-7195

(3) Estudiante de Derecho de la Universidad Santo Tomás, Bucaramanga, Colombia. Auxiliar de investigación del Instituto de Victimología y del Consultorio Jurídico de la Universidad Santo Tomás, Bucaramanga, Colombia. Miembro del colectivo de estudios Pluriverso.

(4) Estudiante de Derecho de la Universidad Santo Tomás, Bucaramanga, Colombia. Auxiliares de investigación del Instituto de Victimología y del Consultorio Jurídico de la Universidad Santo Tomás. Bucaramanga, Colombia. http://orcid.org/0000-0001-9124-1149

(5) Estudiante de Derecho de la Universidad Santo Tomás, Bucaramanga, Colombia, Auxiliar de investigación del Instituto de Victimología y del Consultorio Jurídico de la Universidad Santo Tomás, Bucaramanga, Colombia, Miembro del colectivo de Estudios Pluriverso. http://orcid. org/0000-0003-1923-6091 


\section{R E S U M E N}

En este artículo se expondrán reflexiones críticas sobre la naturaleza de las categorías binarias de reconocimiento y exclusión que han sido hegemónicas en el relato histórico del conflicto en Colombia. A partir de estas categorías antagónicas se ha construido una visión estrecha de la realidad, cuyo resultado fue la intensificación de las hostilidades entre actores sociales, que fueron radicalizándose paulatinamente. La herencia recibida tras más de medio siglo de violencia es una sociedad fragmentada que desde la interiorización de valores contrapuestos construyó un ethos cultural arraigado en el odio por el adversario. Las visiones estereotipadas del "otro", del enemigo, y las concepciones arquetipo de los actores armados, proyectadas desde dos bandos, han sido acompañadas por simplificaciones de la realidad.

PALABRAS CLAVE: narración del conflicto armado, formación del discurso histórico, categorías binarias, prácticas hegemónicas. 


\section{A B S T R A C T}

This paper exposes critical reflections on the nature of binary categories of recognition and exclusion that have been hegemonic in the historical narration of the conflict in Colombia. From these antagonistic categories a narrow view of reality has been constructed, whose result was the intensification of hostilities between social participants that gradually radicalized. The established legacy after half a century of violence is that of a fragmented society that built a cultural ethos rooted in the hate of the adversary from the internalization of opposed values. The stereotyped views on the "other", the enemy, and the archetype conceptions of the armed participants projected from two sides have been accompanied by simplifications of a reality.

KEY WORDS: narration of the armed conflict, formation of the historical discourse, binary categories, hegemonic practices.

\section{R E S U M O}

Expõem-se algumas reflexões críticas sobre a natureza das categorias binárias de reconhecimento e exclusão que têm sido hegemônicas no relato histórico do conflito na Colômbia. A partir dessas categorias antagônicas, tem-se construído uma visão estreita da realidade, a qual resultou na intensificação das hostilidades entre os atores sociais, que foram se radicalizando gradualmente. A herança recebida depois de mais de meio século de violência é uma sociedade fragmentada que, desde a internalização de valores contrapostos, tem construído um ethos cultural fundado no ódio pelo adversário. Visões estereotipadas do "o outro", o inimigo, e concepções arquetípicas dos atores armados projetadas desde ambos os bandos, têm sido acompanhadas de simplificações da realidade.

PALAVRAS CHAVE: narrativa do conflito armado, a formação do discurso histórico, categorias binárias, práticas hegemônicas. 


\section{N T R O D U C C I Ó N}

Este trabajo es un esfuerzo por comprender la influencia que han tenido categorías determinantes al momento de pensar el conflicto armado interno en Colombia, y examinar cuáles serían los insumos teóricos que permitirían una revisión crítica de su naturaleza y su estructura discursiva. La idea inicial es formular una hipótesis sobre la forma en la cual las categorías han construido de manera excluyente, hegemónica y estigmatizada discursos del conflicto, lo que podría haber incidido o influido en la perpetuación de la violencia. Y por ende, podrían repercutir en las lecturas sobre la firma del fin del conflicto entre el Gobierno nacional y las FARC.

Se pretende verificar si esa es una premisa válida y, en la medida de lo posible, ver si es factible arrojar, mediante una revisión teórica y del análisis del lenguaje, información que pueda esclarecer de alguna forma un conflicto de más de medio siglo y cuya información se percibe en muchos casos como poco fiable. El oscurantismo presente en la información sobre los relatos de la violencia asociados al conflicto armado en Colombia es un factor que invita a relativizar la fiabilidad de las informaciones oficiales y de los medios de comunicación.

Las verdades históricas de la violencia armada a través de categorías duales han ocultado las diversas formas de comprensión del conflicto, obviando factores fundamentales como la cuestión de la tierra y las circunstancias e idiosincrasia propias de quienes enfrentaron el conflicto. Entendemos que la reducción del conflicto 
a una guerra del Estado contra narcoterroristas o a una legítima lucha en defensa frente al imperialismo económico transnacional, al margen de constituir una imagen folletinesca, mutila gravemente la interpretación del fenómeno de la violencia asociada a la guerra, al tiempo que menosprecia la memoria de quienes han sobrevivido al conflicto armado.

\section{El discurso de la verdad y la política de la historia}

La construcción de una relación antagónica de categorías en el plano lingüístico repercute en la confrontación material de prácticas discursivas con consecuencias sociales en distintos niveles. El vínculo se establece entre las distintas dimensiones del discurso político permeado por una ideología totalizante, y los procesos cognitivos de asociación que ocurren en el imaginario social del colectivo que asume como ciertas las representaciones heredadas del discurso político. Vemos que, por definición, las prácticas ideológicas sociales están basadas en ideologías definidas como representaciones mentales compartidas de algún tipo, de manera tal que podrían ser comparadas con la forma en la cual el uso del lenguaje está basado en una gramática compartida o reglas de conversación. En este sentido, las ideologías en su carácter de recursos cognitivos socialmente compartidos son fundamentales para las prácticas sociales, la interacción y para las relaciones intra e intergrupales (Van Dijk, 2005, p. 22).

Lo anterior significa que lo político y lo social resultan ser una construcción lingüística compartida que crea un juego de intereses ideológicos desde una perspectiva totalizante. En este proceso se encubren intereses que buscan imponer su propio punto de vista como objetivo, aparentemente desinteresado, pero según el autor en realidad, lo que existe es el punto de vista de los sujetos interesados. Así es que los hechos, aunque sean unos solos, son narrados a través de versiones que dependen de las diversas interpretaciones de cada uno de los observadores. El registro de los hechos varía dependiendo de los intereses del narrador, sin embargo, aquel narrador que tiene mayores medios de difundir su interpretación 
puede tener una mayor credibilidad y su versión podría llegar a institucionalizarse y hacerse oficial.

El intento por escribir ampliamente y a través de diversas voces el conflicto armado, implica un esfuerzo mayor de quienes reconstruyen e interpretan las realidades de aquellos que vivieron la violencia. Para algunos autores como Castillejo (2007) y Laplante (2007) existe una tendencia a conceptualizar ciertos tipos de violencia, a legitimar ciertos actores como víctimas o como victimarios; se escogen unas narrativas y se inscriben en el informe que pretende reconstruir como un todo, una memoria oficial y legítima de lo que realmente pasó. Pero también excluyen individuos y discursos que, bajo ciertos parámetros, pueden resultar inconvenientes, dependiendo del momento histórico y político determinado. Lo que plantea la narrativa de un discurso se asemeja al trabajo de un pintor.

Un paisaje pintado no se compone de campos, arroyos y nubes, sino, según la óptica deconstructivista, sólo de pinceladas sobre el lienzo que materializan signos, es decir, la representatividad de los elementos naturales del paisaje depende de la manera en que el pintor manipula los signos por medio de sus pinceladas y no de la realidad física del paisaje (Derrida, 2001).

De acuerdo con este planteamiento los discursos dependen de quien los construye, de cómo se haga uso de los signos o símbolos, en últimas, la verdad oficial dependerá de cómo se utilicen las categorías y de sus contenidos. Siguiendo a Derrida (1998) el problema del lenguaje radica en la cobardía del vocabulario. En ese sentido, la historia del mundo ha producido incluso la idea de mundo, la idea de origen del mundo a partir de la diferencia entre lo mundano y lo no-mundano, el afuera y el adentro, la idealidad y la no-idealidad, lo universal y lo no-universal, lo trascendental y lo empírico.

Es por esto que Foucault (2001) advierte que debemos mirar lo que está debajo de la historia, la infinitud del relato, que está tratando de ser reducido, en este caso particular, por una comprensión muy estrecha del conflicto. El cómo contar la historia tiene un papel protagónico, pues esta historia se adapta a los discursos de poder, se legitima a través del saber, la verdad de los hechos y con esto la designación de prácticas y dispositivos 
específicos de dominación. En los discursos de los dictadores, las remisiones a la historia son ejemplo de cómo opera el poder. Hitler en Alemania, Franco en España o Milosevic en Yugoslavia, muestran la importancia que tiene la orientación de la historia, para conseguir ciertas actitudes en las masas y los pueblos.

Alain Badiou (1996) plantea que el Nazismo funcionaba a través de la negación de la humanidad de los sujetos: la política nazi definía claramente lo humano a partir de lo inhumano y que, para ella, la realización racial de los arios se construía a partir de la subhumanidad judía. Los nazis sostenían que la vida digna y creadora del alemán normal era la negación de la vida obscura y vana del loco. Estaban convencidos de que lo humano sólo se afirma por su negación, y de que era preciso eliminar de la humanidad todo lo que ella incluía de sub-humanidad (los judíos) o de inhumanidad (los locos).

Pensemos ahora en el proceso de conquista en América en donde se defendió la existencia de la servidumbre natural entre los hombres con el argumento de que los verdaderos hombres son libres y los subhumanos (indígenas), por su condición inferior, pueden ser esclavizados, este argumento sirvió para sustituir el orden establecido e imponer el poder de la corona española a través de la evangelización del cristianismo. Los relatos de los cronistas de la época describen que:

América padece una naturaleza pervertida, decadente; el hombre que en ella vive es un perfecto degenerado que piensa como un niño y tiene el escaso vigor del viejo. El hombre de América no posee sensibilidad, es incapaz de todo progreso mental, vegeta como un incurable haragán casi a nivel de las plantas, a través de esa descripción se justificó el aniquilamiento de millones de Indígenas amerindios, ya que la definición de humanidad se limitaba a los europeos, los indígenas eran subhumanos (Gómez, 2006).

En Colombia, por otra parte, las guerras posteriores a la Independencia y al proceso colonial, no fueron guerras de fronteras, han sido enfrentamientos sucedidos dentro del país. Es por esto que se ha tenido que hacer uso de otras categorías en relación con el sujeto político: Santanderista-Bolivariano, Federalista-Centralista, 
Liberal-Conservador, Comunista-Capitalista. Lo que produjo el establecimiento de jerarquías de poder a través del uso de dispositivos que buscan caracterizar cierto tipo ideología para realizar el subsecuente proceso de inclusión y exclusión de sujetos.

En este punto el antagonismo "es entendido como la relación entre dos objetividades en la que una es negada por la otra" (Cazau, 1996). Bajo esta óptica las fronteras antagónicas constituyen el terreno donde surgen las identidades colectivas, pues el "otro" marca mi identidad. La alteridad es el elemento frente al cual me identifico, pero negándolo. El antagonismo pone de manifiesto el recuerdo de la contingencia, de allí su función reveladora que desnuda el origen político de todo ordenamiento. Los puntos antagónicos van a ser múltiples y que cualquier construcción de una subjetividad popular tendrá que comenzar a partir de esa heterogeneidad. Con respecto a esto Badiou, citando a Levinas, sostiene que:

\begin{abstract}
la metafísica ha ordenado el pensamiento siguiendo la lógica de lo Mismo, el primado de la sustancia y de la identidad. Pero, según él, es imposible reunir un pensamiento auténtico de lo Otro (y por consecuencia una ética del lazo con los otros) a partir del despotismo de lo Mismo, incapaz de reconocer a este Otro. La dialéctica de lo Mismo y de lo Otro, considerada "ontológicamente" bajo el primado de la identidad consigo mismo, organiza la ausencia del Otro en el pensamiento efectivo, suprime toda verdadera experiencia del otro, y cierra el camino para una apertura ética de la alteridad (Badiou, 1996).
\end{abstract}

Estas identidades son valoradas y caracterizadas de acuerdo con sistemas de verdad etéreos, los cuales se materializan en discursos, que a su vez diseñan estrategias para reproducir prácticas de legalidad y legitimidad. En palabras de Gaete, se observa que "la historia está llena de ejemplos de principios de legitimidad que pretenden estar basadas en verdades eternas e incuestionables; verdades que, sin embargo, son controladas por los retóricos del poder" (Gaete, 1993, p. 3). Lo anterior desarrolla la idea con la cual se construyen las historias nacionales, se sustentan en el ejercicio de poder de quien la implementa, con el fin de justificar e instaurar su visión correcta del mundo; lo que conlleva a la hegemonización de los hechos y análisis que alimenta dicha construcción histórica. 
La búsqueda de verdad se convierte en la búsqueda y reconocimiento de sucesos que construyen una versión políticamente correcta de la historia, en la que se opaca y se destruye cualquier alteridad que contravenga el statu quo. Así pues, mediante el simple acto de nombrar de determinada manera el actual conflicto colombiano desde el locus del poder presidencial, se hace política de la memoria y del olvido y se construyen imágenes discursivas del enemigo y del Estado mismo (Orozco, 2005, p. 173).

En los intentos por construir la verdad en los procesos de transición se utiliza un lenguaje basado en la imposición de valores, por medio de la implementación de unas categorías genéricas que responden al mantenimiento del poder de quien utiliza este discurso (Antequera, 2011). Estas discursivas son fijadas como ciertas por medio del sistema jurídico que legitima esa verdad, estos discursos obedecen a su vez a periodos históricos en donde se diseñan dispositivos para reproducir un saber determinado, pero también unas prácticas específicas; por ejemplo, la lectura que se realiza del conflicto armado y la caracterización de sus actores por parte de algunos medios de comunicación en Colombia, varía según el periodo histórico que se analice, muchas veces debido a ciertos intereses que se desprenden del discurso institucional.

Esperanza Najar (2009) considera que la aparente contraposición entre paz y justicia no corresponde a intereses políticos concebidos con anterioridad, sino que esta tensión corresponde a la aplicación de términos legales determinados por principios preexistentes del Estado de Derecho moderno. Los procesos de posconflicto a través de la Justicia Transicional tienen como fundamento una visión hegemónica de la legalidad del mundo, sustentada en un sistema de valores imperante en el plano moral, los Derechos Humanos, que como expone Enrique Haba son:

fórmulas que se mueven antes bien en el plano axiológico que, en él de lo empírico descriptivo y cumplen una función básicamente 'emocionalizante' (...) Si alguna de estas calificaciones es aceptada para el objeto en cuestión, ella obra como un fundamento inimpugnable a los ojos de mucha gente, incluso de filósofos. Se supone que no requieren justificación ulterior, que no admite discusión, es decir, son de un orden sacralizante, obran a modo de 'términos-bandera', o sea, que 
tienden a suscitar una adhesión inmediata y no la discusión en torno a la legitimidad de lo presentado bajo esas etiquetas (Haba, 1983, p. 223).

De acuerdo con lo anterior, los Derechos Humanos son verdades etéreas, incuestionables a partir de las cuales se instaura la verdad histórica oficial en el posconflicto. Sin embargo, los Derechos Humanos restringen desde su naturaleza la aproximación al relato de otras subjetividades coparticipes del conflicto armado. A través de su forma emotiva los Derechos Humanos crean ilusiones de sociedades ideales perfectas, pues en palabras de Haba (1983) se crea una verdad absoluta a la cual se adhiere la sociedad de forma casi espiritual sin considerar los contenidos ideológicos que están tras bambalinas del discurso de los Derechos Humanos, que se instauran de forma inmediata en el imaginario colectivo, demostrando así el poder de imposición que tienen ciertos saberes como el económico o el militar que acogen el discurso de los Derechos Humanos como mascarada para mantener su posición.

Los Derechos Humanos (DH) son permitidos en tanto sirvan también para otros propósitos, como justificar la intervención militar al traducirla en "estabilización" o "ayuda humanitaria". Así también, los DH son viables cuando son lo suficientemente flexibles para que en casos "de emergencia", sean obviados o puedan considerar la toma de medidas especiales como la tortura y violaciones a la privacidad y libertad de los ciudadanos (el caso de las leyes aprobadas en Estados Unidos luego del 11 de septiembre). Es lo mismo para la democracia, en la idea que se expresa frecuentemente que dicho régimen 'está bien', si se limpia de los "excesos populistas" y es practicada sólo por aquellos que están lo suficientemente "maduros" (Barrantes, 2008, p. 4).

Este lenguaje legitima y legaliza una versión hegemónica de las instituciones y del Estado que son quienes crean un relato histórico de la verdad, a través de un dispositivo jurídico como los Derechos Humanos que se proyectan como el horizonte moral del sistema social, y que son eficaces únicamente a la luz del procedimiento judicial y los mecanismos de defensa que se 
crean con la Justicia Transicional en épocas del posconflicto ${ }^{1}$. Esta función protectora del Derecho y de las instituciones judiciales se puede enmarcar dentro de una lógica de autoreferenciación que facilita el tránsito de una ideología legitimadora de ciertas prácticas discursivas dominantes como los Derechos Humanos, a través del papel que juegan las Cortes como productoras de sentido ${ }^{2}$. De acuerdo con esto:

Las Cortes gozan de toda autoridad incluso moral para dictar sus resoluciones y sus opiniones consultivas, y la institución, su origen histórico y su labor, son revestidas de trascendencia y vital importancia para la región y el mundo; importancia que es recalcada algunas veces por los mismos jueces en sus resoluciones, en su afán por constantemente reafirmar la credibilidad de la institución. Las Cortes se vuelven, al estilo que menciona Schumpeter con la democracia, en un ícono de esperanza en el bien de la humanidad tanto para quienes en ella trabajan, como a quienes acuden a ella (Barrantes, 2008, p. 204).

Bajo esta óptica, la verdad histórica podría responder a razones teórico-institucionales definidas por intereses e ideologías políticas, donde la responsabilidad del Estado y de la sociedad se diluye en

1 En la sentencia C-250 de 2012 de la Corte Constitucional de Colombia se decidió que en el contexto de la Justicia Transicional era compatible con el derecho a la igualdad distinguir entre víctimas del conflicto acudiendo a un criterio temporal: se tiene que el límite temporal previsto en el artículo tercero, no es una fecha arbitrariamente excluyente porque, precisamente, cubre la época en la cual se produjo el mayor número de violaciones a las normas de derechos humanos y de derechos internacional humanitario, el periodo histórico de mayor victimización.

2 Tal es el caso de la sentencia C-781 de 2012, donde la Corte Constitucional da una concepción de las calidades que una persona debe tener para ser reconocida como víctima del conflicto armado. La Corte Constitucional ha examinado el contexto en el cual se produce la vulneración de los derechos de las víctimas y ha reconocido que se trata de víctimas del conflicto armado cuando los hechos acaecidos guardan una relación de conexidad suficiente con este. Desde esa perspectiva ha reconocido como hechos acaecidos en el marco del conflicto armado (i) los desplazamientos intraurbanos, (ii) el confinamiento de la población; (iii) la violencia sexual contra las mujeres; (iv) la violencia generalizada; (v) las amenazas provenientes de actores armados desmovilizados; (vi) las acciones legítimas del Estado; (vii) las actuaciones atípicas del Estado; (viii) los hechos atribuibles a bandas criminales; (ix) los hechos atribuibles a grupos armados no identificados, y $(x)$ por grupos de seguridad privados, entre otros ejemplos. Si bien algunos de estos hechos también pueden ocurrir sin relación alguna con el conflicto armado, para determinar quiénes son víctimas por hechos ocurridos en el contexto del conflicto armado interno, la jurisprudencia ha señalado que es necesario examinar en cada caso concreto si existe una relación cercana y suficiente con el conflicto armado interno. 
conceptos y presupuestos inmersos en una matriz interpretativa que legitima la violencia simbólica, la cual categoriza y define los límites de algunas subjetividades que, como en el caso colombiano, están preconcebidas en la representaciones como los "otros", a quienes otorgamos un valor de acuerdo con las reglas del juego ideológico del discurso. La manera como son descritos los actores en los discursos también depende de nuestras ideologías. Tendemos a describir a los miembros de nuestro grupo de manera neutral o positiva, y a los miembros de otro grupo de manera negativa. Igualmente, mitigamos descripciones negativas de miembros de nuestro propio grupo, y daremos énfasis a las características negativas atribuidas a otros (Van Dijk, 2005, p. 38).

En el acontecer histórico del posconflicto, la sociedad colombiana se enfrentará al reto de transformar la narrativa vivencial de la guerra y modificar las reglas discursivas de la ideología política dominante. Comprender hoy el conflicto en Colombia sigue siendo problemático porque es recurrente la construcción de versiones que apelan a imaginarios y estereotipos que anulan los universos culturales de quienes vivieron la guerra. En el caso concreto de quienes se denominan victimarios, es casi imposible entenderlos más allá de la idea de maldad, una construcción que los ubica como el enemigo. Las prácticas discursivas que permearon el mundo político durante los años del conflicto crearon categorías dicotómicas como la de héroevillano que se instalaron con mayor fuerza en un ambiente social polarizado donde los medios de comunicación y la propaganda institucional crearon una serie de símbolos alrededor del carácter redentor de quienes defienden la "democracia" a la vez que acentuaron la corrupción de aquellos que transgreden el orden democrático institucional a través de las armas. Es así que conceptos antitéticos se convierten en símbolos que a su vez refuerzan comportamientos sociales de aprobación o rechazo hacia los sujetos enfrentados.

El andamiaje teórico anteriormente expuesto es el sustento sobre el cual puede ser corroborada la hipótesis de trabajo. Sin embargo, es necesario hacer un acercamiento a elementos empíricos que pueden reafirmar el uso de ciertos conceptos y categorías determinantes de la narrativa del conflicto, además de soportar con mayor rigor la hipótesis sobre la que gira la reflexión. 


\section{Las huellas de las discursivas totalizantes en el relato del Conflicto Armado colombiano}

Los discursos hegemónicos sólo pueden dar cuenta de una verdad limitada y acomodada, ya que en ellos no se permite la coexistencia de diferentes formas a la vez, porque las categorías con las cuales fueron construidos se valen de contenidos absolutos. La categoría victimario, por ejemplo, sólo puede entenderse a través del contenido que en ella se ha vertido y con el cual es entendido. Criminal será así, la representación con la cual es asociado el victimario. Cuando se piensa en la categoría de victimario se piensa en un inhumano, alguien cruel y despiadado que se ha despojado de su humanidad para convertirse en un loco, monstruo o asesino.

De acuerdo con esto vamos a exponer la literalidad de algunos discursos emitidos por una parte de la Institucionalidad Gubernamental, representada por el Centro Nacional de Memoria Histórica creado por la Ley 1448 de 2011. Por otro lado, se traerán apartes de artículos y editoriales de un periódico y una revista de amplia circulación como los son El Tiempo y la revista Semana, que transmiten un mensaje significativo a la población sobre las características que describen a los actores el Conflicto Armado colombiano.

Para comenzar resulta pertinente analizar lo planteado en los informes Basta ya, escrito por el Centro Nacional de Memoria Histórica y la Contribución al entendimiento del conflicto armado en Colombia elaborado por la Comisión Histórica del Conflicto, con el fin de ilustrar el uso de la categoría victimario dentro de estos informes, como una forma de caracterizar a los responsables del conflicto armado interno en Colombia.

En el informe Basta ya se narra lo acontecido entre 1962 y 1963, tiempo durante el cual se le otorgó a las fuerzas militares un alto nivel de independencia para combatir aquello que ponga en riesgo la institucionalidad, utilizando mecanismos de intervención directa en las zonas donde se formaron las llamadas "repúblicas independientes" (Histórica, 2013). El Estado veía en estas repúblicas la exteriorización de la amenaza comunista en pleno auge de la 
guerra fría. En medio de la narración y contextualización del Plan Lazo $^{3}$ este informe concluye su relato así:

La acción militar hacía parte de una intervención integral, orientada a desplegar la capacidad del Estado para atender con sus servicios a esas regiones afectadas por la violencia, que hacía parte tanto de una lógica social como de una lógica de lucha anticomunista (Histórica, 2013, p. 121).

Lo curioso de lo expresado en el informe es el uso del lenguaje al describir la intervención militar en el campo, a la cual se le da una dimensión social y cívica. Sin embargo, resulta aún más significativo que no se habla de la génesis de las repúblicas independientes y el papel que jugaron en este proceso las políticas agrarias de latifundios y distribución desigual de la tierra. Por otra parte, es de resaltar como la narración muestra el accionar del ejército como legítimo dentro de la lucha anticomunista; generando así la categorización inicial del comunismo como una amenaza a la legitimidad del Estado de Derecho, lo que enmarca al comunista como la representación del victimario.

En la década de 1990 surgió una nueva amenaza: el narcotráfico, en el informe Basta ya se describe el conjunto de estrategias que el Gobierno implementó para combatir bajo ciertos criterios jurídico-políticos la amenaza narcotraficante, como se plasma a continuación:

El gobierno afrontó el desafío sin precedentes derivado de la guerra que los grandes carteles de la droga le habían declarado al Estado para combatir la extradición. En ella, bajo la justificación de estar librando una batalla contra el narcoterrorismo, el primer gobierno en el marco de la nueva Constitución continuó por el camino de la excepcionalidad jurídica para endurecer las penas, introducir innovaciones procesales que chocaban con los más elementales principios del garantismo penal, utilizar el Estatuto Antiterrorista (aprobado

3 Plan Lazo diseñado por el Ministro de Defensa, General Alberto Ruiz Novoa, se dio inicio a la lucha contra los rebeldes de Marquetalia. 
bajo el gobierno de Virgilio Barco) para recortar las libertades públicas de otros sectores sociales distintos a los narcotraficantes y afectar significativamente el principio de igualdad ante la ley penal (Histórica, 2013, p. 223).

La lógica que opera en la narración es muy similar a la que relata la intervención militar en las repúblicas independientes, ya que se describe a un Estado haciendo uso de sus facultades ordinarias y extraordinarias para contener una amenaza pública, sin socavar en los orígenes de la problemática económica y social causante del narcotráfico. Esta lógica permitió particularizar a los actores del conflicto en narcotraficantes o grupos relacionados a estas actividades para combatirlos por medio de las fuerzas armadas gubernamentales. En conclusión tenemos un nuevo tipo de victimario-enemigo como categoría histórica antepuesta siempre al Estado.

Otra de las categorías que emerge en la narración del conflicto armado en el mismo circuito, victimario-enemigo, es la del terrorista, que aparece en el relato histórico con el informe de las primeras intervenciones de Estados Unidos a través del Plan Colombia y la lucha contra el terrorismo, en un contexto internacional tenso tras los atentados del 11 de septiembre de 2001, así describe el informe del Centro Nacional de Memoria Histórica lo sucedido en aquel tiempo:

Para el año 2001, el contexto internacional se había venido modificando sustancialmente a partir de los atentados terroristas del 11 de septiembre en Estados Unidos, que crearon un clima internacional cada vez menos dispuesto a tolerar las actividades terroristas antes justificadas en causas políticas. En diferentes sectores de Estados Unidos se empezó a abrir camino la idea de ampliar el uso de los recursos del Plan Colombia, dedicados exclusivamente al combate contra el narco-cultivo y el narcotráfico, para utilizarlos también en el combate abierto contra los grupos guerrilleros. En adelante, la amenaza narcoterrorista cambió profundamente su significado y quedó vinculada al conflicto armado (Histórica, 2013, p. 169).

Esta categoría permitió que se pasara de una lucha contra el narcotráfico a una lucha contra el terrorismo vinculada 
directamente con la otrora amenaza comunista, lo que formaba la triada que caracteriza al sujeto más peligroso para la institucionalidad estatal, el guerrillero-narco-terrorista, que tiene un tratamiento diferenciado en material de Derecho Internacional Humanitario, debido a que deja de ser un simple actor al margen de la Ley o beligerante y se convierte en terrorista, dándole al Estado la facultad de actuar de una forma más agresiva para mitigar y combatir este tipo de victimario-enemigo.

En conclusión, el Informe asigna al Estado una legitimidad reforzada para actuar en consecuencia frente a cada una de las amenazas históricas sin reconocer las múltiples miradas de los coparticipes del conflicto; y desconociendo la compleja génesis detrás de cada uno de los fenómenos descritos: el primero, la amenaza anticomunista, que se gestó entre las décadas de 1950 y 1980; la segunda, la amenaza del narcotráfico y el narcoterrorismo; y por último, la amenaza terrorista, que permeó el conflicto armado colombiano por medio de las demandas internacionales, en especial de Estados Unidos y el Plan Colombia. Estas tres categorías permitieron identificar la imagen del victimario como aquel que trasgrede la institucionalidad desde su accionar. Esta distinción y particularización del victimario se justifica en la discursividad hegemónica en un determinado momento histórico, que justifica todo el accionar del Estado al momento de combatir al enemigo.

La relatoría escrita por Vicente Torrijos para el informe Contribución al entendimiento del conflicto armado colombiano, realizado por la Comisión Histórica del Conflicto y sus Víctimas, brinda algunos elementos de análisis. En esta relatoría se hace una alusión a las dinámicas y el desarrollo del conflicto armado en Colombia, pero resulta interesante la forma en la que se explica la dinámica combativa entre el Estado y la guerrilla, tal como se observa a continuación:

Las fuerzas estatales se adaptan a ese tipo de amenaza y desarrollan, con el apoyo intermitente de potencias aliadas, iniciativas antisubversivas [tradicionales y experimentales] que, al tener su origen en un sistema democrático [occidental y liberal, fundado en la tradición judeo-cristiana], se orientan a proteger al ciudadano de las acciones terroristas (Torrijos, 2015, p. 653). 
En este apartado se puede ver como el autor utiliza ciertas categorías para determinar uno u otro grupo. Por un lado, se muestra el accionar insurgente en los marcos del accionar terrorista, siendo éste el accionar del victimario de manera general, como la acción ilegítima contra el Estado constituido; y por el otro el accionar legal y legítimo del Estado y sus fuerzas militares en pro de mitigar y erradicar el accionar terrorista del grupo insurgente. Para reafirmar esta idea, el relator expone su definición de accionar terrorista de la siguiente forma:

Acciones terroristas que, generalmente, se destinan a que los insurgentes consigan ejercer influencia local, regional o transfronteriza a cualquier costo, o sea, afectando a la población civil en su conjunto al 'otro', es decir, a aquellos sectores sociales o individuos que no comulgan con su parecer político o con la violencia como metodología política (Torrijos, 2015, p. 653).

Esto reafirma la idea de la categorización del victimario, pero también se identifica la categorización del "otro", desde el punto de vista del insurgente, terrorista o victimario, como aquel que confronta los parámetros de normalidad establecidos por el Estado. Lo anterior lleva a concluir que, desde la óptica de este relator, hay dos bandos en este conflicto, calificados como actores legítimos e ilegítimos. Se excluye al aparato estatal de su responsabilidad en los hechos dado que "Los agentes del Estado han sido castigados de acuerdo con la Ley. No ha existido, ni existe, una política de Estado que fomente las violaciones" (Torrijos, 2015, p. 684).

Lo que lleva a decir que para este autor los victimarios son los grupos insurgentes que afectaron a la población civil por medio de actos terroristas, mientras el rol del Estado es un rol garante y protector de la población civil ajena al conflicto. El Estado totalmente legítimo y legal no puede estar inmerso en hechos que vayan en contravía a esta función, por lo que aparta de su estructura a aquellos inmersos en esta clase de actos, teniéndolos categorizados como otros o alienados; dando como resultado un análisis dicotómico del conflicto armado narrado a partir categorías antagónicas.

La sociedad como receptora del mensaje entiende que existe un soldado quien hace un uso legítimo de las armas para contribuir 
al establecimiento de una sociedad democrática y que es reconocido como héroe en los escenarios públicos y, por otro lado, está el guerrillero, el actor armado al margen de la ley, quien se alzó contra el Estado legítimamente constituido, haciendo un uso criminal de las armas, y a quien la sociedad lo tiene por delincuente y terrorista.

En cuanto a la categoría de víctima, Vicente Torrijos también adopta una concepción muy acorde con la del Estado, la cual está ceñida a los lineamientos internacionales en cuanto a la vulneración de los Derechos Humanos y el Derecho Internacional Humanitario. Esta relación se manifiesta de la siguiente forma:

\begin{abstract}
De acuerdo con esta definición, plenamente coincidente en Colombia con el artículo 3 de la Ley 1448 de 2011 [de víctimas y restitución de tierras] y las sentencias de la Corte Constitucional [370 de 2006, C-578 de 2002, C-052 de 2012, C-250/12, C-253A/12, C- 781/12, C-462/13], víctima es "toda persona que haya sufrido daños, individual o colectivamente, incluidas lesiones físicas o mentales, sufrimiento emocional, pérdidas económicas o menoscabo sustancial de sus derechos fundamentales, como consecuencia de acciones u omisiones que constituyan una violación manifiesta de las normas internacionales de derechos humanos o una violación grave del derecho internacional humanitario" definición a la que queda integrada "la familia inmediata o las personas a cargo de la víctima directa y las personas que hayan sufrido daños al intervenir para prestar asistencia a víctimas en peligro o para impedir la victimización" (Torrijos, 2015, p. 683).
\end{abstract}

De igual forma, el Procurador General de la Nación, Alejandro Ordoñez, a través de discursos mediáticos sobre las políticas del gobierno con relación al proceso de paz, y en oposición frente a algunos asuntos que se han acordado en la mesa de negociaciones en La Habana, ha intentado legitimar su discurso a través de la concepción de víctima y victimario empleada en Colombia, tal como lo hace en la siguiente afirmación.

La verdad no se negocia, al igual que no se negocian los derechos de las víctimas, ello en el contexto de la reiterada jurisprudencia de la honorable Corte Constitucional y en el derecho que tiene la 
sociedad colombiana frente a la verdad del conflicto armado y los métodos empleados por los victimarios que actualmente adelantan negociaciones con el Gobierno. agrego que "La verdad no puede ser la que quieren los victimarios de las FARC", sentenció el procurador Ordóñez Maldonado, alertando que este tipo de ejercicios ocultan la responsabilidad del grupo terrorista en graves violaciones a los Derechos Humanos a través de delitos de lesa humanidad, crímenes de guerra y genocidios (Nación, 2014).

La lectura que realizan medios de comunicación como la revista Semana o el periódico El Tiempo, del conflicto armado, muta según el momento en que se analicen estos discursos, y aunque los marcos de análisis varían, se mantiene la polarización. Los medios de comunicación parten de ciertos contenidos desde los cuales reproducen su lectura de la guerra y de sus actores, por ejemplo, es diferente el uso que se hace en los años 1990 y 2000 sobre la categoría Narcoterrorista, a la que se hace entre los años 2002 y 2010, ya que en este último periodo esa categoría se sobrereproduce, ello debido a que los intereses estatales varían como lo hacen las discursivas de los actores institucionales.

En la década de 1980 los grandes carteles del narcotráfico tuvieron gran protagonismo en las dinámicas sociales y políticas de Colombia, la emergencia de nuevos carteles como el de Medellín y posteriormente de Cali, hizo que la categoría de Narcotraficante tuviese que utilizarse con mayor frecuencia dentro de las discursivas de las instituciones y de los medios de comunicación, en la década de 1990 los grupos paramilitares comenzaron a tener mucha mayor fuerza, sobre todo los paramilitares en el año 1998 con el crecimiento de sus acciones armadas.

Para estas fechas (años 90) el discurso de los medios de comunicación leía la situación y la caracterizaba como una confrontación entre tres aristas que emergían: mafia, guerrilla, paramilitares, este ajedrez político puede reconocerse en algunas publicaciones de aquella época, como la siguiente que se extrae del periódico El Tiempo, en un artículo denominado "Narcoterrorismo y paramilitares esperan a Gaviria”.

Tras el velo romántico que envuelve el cambio de Presidente adobado esta vez al ritmo de rock y caros jóvenes, los cañones 
de la mafia, de la guerrilla y de los paramilitares, cargados de pólvora y también de promesas de paz, esperan ahora que el Gobierno mueva sus fichas. En este dramático juego de ajedrez, la tregua anunciada por Los Extraditables que ya completa ocho días sin el asesinato de policías en Medellín tiene una intención clara: ganar espacio para que el tema de la extradición y, tal vez, la misma guerra al narcotráfico, formen parte de la agenda de la Asamblea Nacional Constitucional (Cañón Moreno, 1990).

En 1994 podemos notar más de estas categorías que comenzaban a presentarse de manera más contundente, Enrique Santos Calderón en un artículo publicado en el diario El Tiempo, exhibe la emergencia de esta categoría denominada paramilitar y la lectura que se hace de ésta:

En su vida y trayectoria, Fidel Castaño representa un fenómeno que está en el meollo de la violencia colombiana. Que no se puede desconocer, si se trata de sentar las bases de una paz realista, estable y duradera. Es el de las autodefensas, hoy mejor conocidos como paramilitares, que nacieron con el auspicio de miembros de las Fuerzas Militares, en un intento por ganar el apoyo de la población civil en regiones donde la guerrilla se había dedicado al secuestro y el boleteo. Las autodefensas son la otra cara de la moneda. Nacieron como respuesta desesperada de ganaderos y campesinos ricos ante los abusos de la guerrilla y hoy cuentan con un innegable apoyo social, e incluso con respaldo de congresistas y dirigentes políticos nacionales y regionales (Santos Calderón, 1994, énfasis añadido).

En el mismo año, la revista Semana publica un artículo titulado "Narcoguerrilla" en donde se pone en relieve el uso de esta categoría que venía reproduciéndose en años anteriores, pero aun sin mucha fuerza o impacto, el autor en el caso de este artículo categoriza enfáticamente a la guerrilla, como una Narcoguerrilla, aún no, como un grupo Narco-terrorista:

Pero aun así los argumentos para desvirtuar la teoría de la narcoguerrilla calaron por algunos años, con el paso del tiempo la sucesiva revelación de caso tras caso, terminó por convencer 
a muchos. Lo sucedido el jueves pasado se enmarca dentro de este proceso, pero en algunos aspectos parece ir más lejos. El incidente se convierte en la comprobación -si aún hacía faltade que las Farc están convertidas en un poderoso cartel, que controlaba hasta la semana pasada uno de los más grandes laboratorios de que se haya tenido noticia en la historia de la narcoguerra (Nación, 1994, énfasis añadido).

En el año 2001, después de los ataques terroristas sufridos por Estado Unidos el 11 de septiembre, el diario El Tiempo publicó un artículo titulado "Son o no son" en el cual se reflexionaba acerca de cuál era el estatus de la guerrilla: grupo terrorista o narcotraficantes, pues en el escenario de un posible diálogo, era necesario categorizarlos para su respectivo trato:

Se da entonces una grave inconsistencia respecto a la cual la organización guerrillera hace bien en demandar una aclaración. Si las Farc son terroristas, Pastrana no puede seguir en tratos con ellas, ni menos aún garantizarles un inmenso e intocable santuario en el Caguán. Hacer tal cosa es violar los compromisos que Colombia adquirió en las Naciones Unidas y en la OEA como parte de la Coalición Antiterrorista Internacional. Pero si, para mantener un proceso de paz que nació muerto, el Gobierno se niega a aplicarles esa calificación, lo menos que puede hacer es exigirles a los Estados Unidos que no las denomine así y que las excluya de la temible lista negra en la que figuran tan ostensiblemente al lado de Ben Laden, de Al Qaeda, de Eta y demás.

Con el narcotráfico sucede algo similar. No se puede tachar a las Farc de narcotraficantes para recibir a través del Plan Colombia una cuantiosa ayuda militar, pero simultáneamente retratarse, entenderse, abrazarse y firmar papeles y acuerdos con los jefes del cartel. Si las Farc trafican con coca y la siembran y la comercian en la zona que está bajo su absoluto control, tal como el Presidente lo aseguró la semana pasada desde el exterior, el tratamiento que se les debe dar no puede ser distinto al infamante y severísimo que se les aplicó a los carteles de Cali y de Medellín. Pero si son fuerzas insurgentes que no se 
han contaminado con esa actividad, que oficialmente quede establecido así para toda clase de efectos dentro y fuera del país (El Tiempo, 2001).

En el año 2004, y con el gobierno de Uribe, "el ajedrez de lo político" cambia y también sus connotaciones. En esta época la guerra ya no se produce con las guerrillas ni con los carteles, ya que se da una ofensiva directa contra las FARC como un grupo Narcoterrorista y una confrontación muy taimada contra los grupos paramilitares, las relaciones con Estados Unidos se estrechan, el combate contra el narcoterrorismo se agenda en el accionar institucional y otros grupos comienzan a perder relevancia dentro de la discursiva institucional, mientras que se mencionan con cada vez más frecuencia al grupo que para entonces era denominado como Narcoterrorista.
Esta semana, el presidente Bush recibirá en Washington al presidente Álvaro Uribe, de Colombia, uno de los más firmes aliados de Estados Unidos en la guerra global contra el terrorismo. Para defender su democracia, Colombia está luchando contra las fuerzas del narcoterrorismo. El presidente Uribe saldrá de la Casa Blanca sabiendo que Estados Unidos continuará apoyando a Colombia en su lucha por la paz, la democracia y la prosperidad (Grossman, 2004).

En este periodo (2002-2010) el cambio de discurso frente a las FARC fue notorio, la categoría se afianzó como una máscara que los determinaba, cualquier razón ideológica quedaba desprovista ante una caracterización que eliminaba cualquier influencia de este tipo de grupos en la geometría política del orden institucional, la doctrina del enemigo se aplicaría en Colombia por medio de una política de confrontación armada, los medios de comunicación seguirían reproduciendo este tipo de discursos y se lograría la sedimentación de la categoría "Narcoterrorista".

En esta doctrina guerrerista el soldado es reconocido como un héroe de la patria, mientras que el narcoterrorista es desprovisto de cualquier humanidad, esto se puede ver reflejado en un discurso del que fuera el presidente de aquella época Álvaro Uribe Vélez y reproducido por revista Semana, en este discurso que tuvo 
ocurrencia en la ceremonia de ascenso de la Escuela de Cadetes General Santander en el año 2007, los policías son caracterizados como héroes:

Ellos, en la carrera que hoy los lleva a ser consagrados como Generales de la República, mientras los colombianos hemos tenido festivos, ellos han estado protegiendo nuestra seguridad; mientras los colombianos hemos tenido vacaciones, ellos han estado trabajando por la tranquilidad; mientras los colombianos podemos reposar en la noche, en el seno de nuestros hogares, ellos han estado vigilando para que no se afecte esa tranquilidad. Son Generales y héroes de la Patria (Uribe Vélez, 2007).

Mientras que los guerrilleros son comparados con el régimen nazi o con Hitler:

¿Qué diferencia hay entre la tortura de nuestros compatriotas, ahora y a lo largo de los 50 años anteriores, la tortura de Ingrid Betancourt, de Gloria Lara, de José Raquel Mercado, de Guillermo Gaviria, de Gilberto Echeverri, qué diferencia hay con las torturas que sufrieron los judíos en los campos de concentración nazi? Por eso algunos europeos tienen que hacer esta reflexión: si hoy tuvieran un Hitler en Europa, no lo dejarían prosperar. (Uribe Vélez, 2007).

Después de los años posteriores y con el ascenso de Juan Manuel Santos a la Presidencia de la República las determinaciones sobre la guerrilla se suavizan, se matizan, esto con el fin de poder establecer los diálogos de paz con el grupo guerrillero, según Santos en un artículo publicado en la revista Semana:

Colombia es un país distinto, que camina por el siglo xxi con buen pie y en el que el progreso social ha generado unas clases medias imprescindibles para su desarrollo. En este contexto, las FARC son, no ya condenables como organización terrorista, sino un auténtico anacronismo que lastra el futuro del país (Santos, 2012).

De esta manera el que fuera la cabeza del gobierno nacional categorizaba a las FARC de una manera diferente, aunque no en todos 
los campos de la institucionalidad esto sucede, el ex presidente Álvaro Uribe Vélez, por su parte, como Senador de la República, advierte que el estatus de las FARC no es otro que, de terroristas, y por su parte, el Procurador General de la Nación los señala de victimarios.

\begin{abstract}
Las FARC adoptaron como política el ataque generalizado y sistemático en contra de la población civil, siendo responsables de graves infracciones al Derecho Internacional Humanitario, las cuales fueron debidamente documentadas y son de conocimiento de la opinión pública nacional e internacional (...) hace un respetuoso llamado a quienes hacen parte de la mesa de diálogos en La Habana para que se reconozca y asuma plenamente la condición victimaria de las Farc en el conflicto armado colombiano y no se desconozcan los derechos de las víctimas ni las garantías de no repetición (Justicia, 2014).
\end{abstract}

Es así como se logra evidenciar que el relato del conflicto en Colombia puede ser elaborado y analizado desde diferentes ámbitos (medios de comunicación, instituciones del Estado, altas cortes, etc.), pero, aunque estos discursos se transformen, conservan categorías y estructuras que mantienen la división sectaria. Además, se debe tener en cuenta la época en que se escribe el relato y también quién la produce, la visión ideológica de la institucionalidad se expresa desde diferentes aristas, como en el Derecho, políticas públicas, enseñanza y educación, lo que genera que el discurso se adapte a esas transformaciones y comience a ser pensado desde el matiz que proponen ciertos grupos de poder.

\title{
Conclusión
}

El momento histórico por el cual atraviesa el país necesita del esfuerzo académico para pensar los marcos de análisis en los que es leída la realidad colombiana, requiere, además de un esfuerzo especial de toda la población por entender el conflicto más allá de una verdad homogénea. El escenario del posconflicto en Colombia nos convoca a entender la manera en que operan ciertas subjetividades emergentes, y vaciar de contenidos las categorías dogmáticas con las cuales se construyó la verdad histórica del 
conflicto. Ese intento por vaciar el contenido esencialista de las categorías como plantea Derrida (1998) a través de una desconstrucción, aspira a mostrar que hay figuras privilegiadas y postergadas por ciertos usos racionales (logos), impuestas por el principio lógico de identidad. Rorty se pregunta: ¿Estamos describiendo las cosas como realmente son? Y la respuesta en el caso del conflicto armado en Colombia es no, las descripciones que se hacen del conflicto son limitadas y ceñidas a intereses políticos, por lo que sería necesario preguntarnos cuáles serán las condiciones en que es posible construir una narrativa pluralista que relate una historia abierta a las visiones de los diversos coparticipes del conflicto armado interno colombiano.

El posconflicto es una oportunidad de trasformar los múltiples contenidos discursivos y significantes que por su naturaleza han facilitado la connaturalización de la violencia. La posibilidad de la terminación del conflicto en Colombia, es apenas lo que podemos decir de la parte fenoménica de un mundo que comienza hacer irreconocible e irrepresentable por los marcos referenciales anteriores, que desarticula el mundo simbolizado, hegemónico durante los años de conflicto, un statu quo de significados que a partir de un juego de diferencias (antagonismos) estableció las reglas del juego político entre los actores sociales representados (identidades). Es justo en este momento histórico donde las categorías duales como víctima-victimario, héroe-terrorista, soldadoguerrillero, provistas de una naturaleza de exclusiones, quedan obsoletas ante la apertura a la contingencia, a lo imprevisible.

Es en los albores de este cambio fundamental donde se sitúa esta reflexión, que antes de intentar ser conclusiva es una invitación a repensar y recrear el país desde sus cimientos descriptivos, a descolocar las palabras y los discursos para confrontarlos con una crítica contundente a su naturaleza. Quizá así podamos enfrentarnos a un porvenir más incluyente y con una perspectiva heterogénea de la historia.

\section{Referencias}

Antequera, J.D. (2011). La memoria histórica como relato emblemático. Bogotá: Rocca S.A. 
Badiou, A. (1996). Reflexiones sobre nuestro tiempo, Conferencia de apertura del xiv Congreso Brasileño de Psiquiatría, noviembre de 1996. Publicado en Buenos Aires: Ediciones del Cifrado, 2000.

Barrantes, M. P. (2008). El fundamento ideológico de los derechos humanos. Crítica ideológica al discurso de la Corte Interamericana de Derechos Humanos. San José: Universidad de Costa Rica.

Cañón Moreno, L. (1990). Narcoterrorismo y paramilitares esperan a Gaviria. El Tiempo. Disponible en: http://www.eltiempo.com/archivo/ documento/MAM-69456.

Castillejo C., A. (2007). La globalización del testimonio: historia, silencio endémico y los usos de la palabra. Revista Antípoda, 4, 76-99.

Cazau, P. (1996). Lo real, lo simbólico, lo imaginario. Buenos Aires: Enseñanza media superior en Psicología, Universidad de Buenos Aires.

Centro Nacional de Memoria Histórica (2013). ¡Basta Ya! Colombia: Memorias de guerra y dignidad. Bogotá: Imprenta Nacional.

Derrida, J. (1998). De la gramatología. México D.F: Siglo Xxi.

Derrida, J. (2001). La verdad en pintura. Buenos Aires/México: Paidós.

El Tiempo. (2001). Son o no son. El Tiempo. Disponible en: http://www. eltiempo.com/archivo/documento/MAM-667534

Foucault, M. (2001). Defender la sociedad. Argentina: Fondo de Cultura Económica.

Gaete, R. (1993). Human Rights and the Limits of Critical Reason. London: Cambridge University Press.

Gómez, J. A. (2006). Antecedentes de lo religioso en América Latina. Bogotá. Universidad Santo Tomás.

Grossman, M. (2004). El apoyo a la democracia colombiana. El Tiempo. Disponible en: http://www.eltiempo.com/archivo/documento/MAM1508093

Haba Müller, E. P. (1983). ¿Derechos humanos o Derecho natural? (Metacrítica de una crítica iusnaturalista a la noción de 'Derechos Humanos'). En Anuario de Derechos Humanos 2. Madrid: Universidad Complutense de Madrid.

Justicia, E. T. (2014). Las Farc deben reconocer su papel de victimarios: Procuraduría. El Tiempo. Disponible en: http://www.eltiempo.com/ politica/justicia/procuraduria-rechaza-que-las-farc-no-reconozcancrimenes-de-guerra-genocidio-y-delitos-de-lesa-humanidad/14787356

Klemperer, V. (2001). LTI La lengua del Tercer Reich. Apuntes de un filólogo. Barcelona: Editorial Minúscula.

Krieger, P. (2004). La reconstrucción de Jacques Derrida (1930-2004). Anales del Instituto de Investigaciones Estéticas, XXVI(84), 179-188

Laplante, L. (2007). Después de la verdad: demandas para reparaciones en el Perú post comisión de la verdad y reconciliación. Revista Antípoda, 4 , $119-145$.

Nación. (1994). Narcoguerrilla. Revista Semana. Sección Nación. 
Najar Moreno, E. (2009). Derecho a la verdad y justicia transicional en el marco de aplicación de la Ley de Justicia y Paz. Bogotá: Ibáñez.

Orozco, I. (2007). Algunos comentarios a la conferencia del Profesor Hauke Brunkhorst. En Memorias del seminario internacional Justicia transicional en la resolución de conflictos y secuestro. Bogotá: Vicepresidencia de la República y Universidad Nacional de Colombia.

Procuraduría General de la Nación. (21 de agosto de 2014). Señor presidente, en una Democracia no puede haber verdad oficial y menos resultado de la imposición de los victimarios de las FARC. Procurador Alejandro Ordóñez. Disponible en: http://www.procuraduria.gov.co/portal/_ Senor-presidente__en_una_Democracia_no_puede_haber_verdad_ oficial_y_menos_resultado_de_la_imposicion_de_los_victimarios_de_ las_FARC___Procurador_Alejandro_Ord__ez.news

Santos Calderón, E. (1994). Los paramilitares y la paz. El Tiempo. Disponible en: http://www.eltiempo.com/archivo/documento/MAM-227239

Santos, J. M. (2012). El radicalismo de Uribe responde a otros tiempos y a otra Colombia: El País de España. Revista Semana. Disponible en: http://www.semana.com/politica/articulo/el-radicalismo-uriberesponde-otros-tiempos-otra-colombia-el-pais-espana/263790-3

Sentencia C-250, D-8590, D-8613, D-8614. Corte Constitucional, 28 de marzo de 2012.

Sentencia C-781, D-8997. Corte Constitucional, 10 de octubre de 2012.

Torrijos, V. (2015). Cartografía del conflicto: Pautas interpretativas sobre la evolución del conflicto irregular colombiano. En Contribución al entendimiento del conflicto armado en Colombia (pp. 652-696). Bogotá:

Desde Abajo.

Uribe Vélez, Á. (2007). Discurso completo de Uribe. Revista Semana. Disponible en: http://www.semana.com/on-line/articulo/discursocompleto-uribe/89915-3

Van Dijk, T. (2005). Política, Ideología y Discurso. Quórum Académico II(2), $15-47$. 